\title{
Social and Religion Paralysis in James Joyce's Short Story The Sisters: A Cultural Reading
}

\author{
Safoura Eskandari \\ Student of Islamic Azad University, Tabriz., Iran \\ jaminuddinmarbun@yahoo.co.id
}

\begin{abstract}
This paper attempts to demonstrate how James Joyce`s short story The sisters reflects notion of social and religion paralysis functions within the framework of cultural materialism at the beginning of the Twentieth century in Irish society. Religion is major concern of cultural studies. Religion as a cultural politics is a dominant factor in shaping mind as well in affecting the framework of literary text. Religion is one of the emerging issues in the modern era and forms the backbone of most literary works. Religion as a theme is seen to influence the operation of those who believe in it. It forms the functional framework that predetermines ones actions and behavior. Williams argues that each kind of activity in fact suffers, if it is wholly abstracted and separated. Politics, for example, has gravely suffered by its separation from ordinary relationships, and we have seen the same process in economics, science, religion and education. Williams defines Residual as some social or cultural practice which has been formed in the past, but it is still active and effective in the present cultural system like organized religion. A residual cultural element is usually at some distance from the effective dominant culture, but it is some part of it which is embedded in cultural system. The concept of emergent for Raymond Williams means the creation of new meaning and values, new cultural practices and new relationships within the dominant structure. It is important to distinguish between those emergent which are elements of new stage of the dominant culture and those which are actually other element or oppositional to dominant system. This study aims to argue that paralysis is a problem and a solution and that sometimes what appears to be an escape from paralysis merely reinforces its negative manifestation. Paralysis cannot be avoided. Rather, it is something that should be engaged and used to redefine individual and social states.
\end{abstract}

Keywords

Cultural Materialism, Religion paralysis, Hegemony, Dissidence,

\section{Introduction}

In James Joyce criticism, and by implication Irish and modernist studies, the word paralysis has a very insular meaning. The word famously appears in the opening page of Dubliners, in "The Sisters," which predated the collection's 1914. Paralysis repeats several time in stagnation in Ireland. In researcher conception, paralysis is functional for The sisters. Sign of such paralysis refers to a kind of passivity of characters in Dublin. The messy spiritual breakdown of modern society declines the chances of spiritual stability and increases 
disorder of once life. Irish society suffers from spiritual sterility that conducts their life and inflicts the Dubliners 'behavior. Such conduct deprives them, making them preys of a superficial world full of delusion and seclusion. Joyce's Dubliners is a spiritually famished prisoner serving time in a barren cell to which there seems to be no key (Lowe-Evans 46). As a cultural nationalist, Joyce's project is to expose a form of paralysis that urges the Irish subject to act within the boundaries of a worldview that is characteristic of hegemony. His solution is to use art as another form of paralysis to disrupt a worldview that is merely instrumental for a dominant regime of production.

In a homeland which had for so long encompassed Catholicism, Joyce made a bold move in attacking it as he did. Both Ireland and the Catholic Church had let Joyce down, meaning that it is very well possible that Joyce could have included Ireland in his anger when he stated forcefully of the Church, "I make open war upon it by what I write and say and do" (qtd. in Lernout 332). Cultural Materialism as a postmodernist critical approach has root in the contextual approaches. It tries to remove the deficiencies of the traditional contextual approaches and to provide a practical and well-organized theory in literary criticism. Some critics believe that the background of Cultural Materialism refers to the Historical oriented approaches, but some others maintain that it is the result of Marxism. It is important that Cultural studies have significant role in the construction of Cultural Materialism.

Contextual approaches were constructed after traditional approaches and New Criticism. Their background goes back to the nineteenth and early twentieth centuries when scholars asked to what extent literary texts were under the influence of the historical, political, economical, philosophical, religious and psychological contexts of their productions. One example of the contextual approaches was Marxist criticism which regards the production of literary texts as "the interface of material and socio-economical circumstances" (Selden 88). Class and economic structures were the particular focus of Marxist critics.

Williams defines Residual as "some social or cultural practice which has been formed in the past, but it is still active and effective in the present cultural system like organized religion" (qtd. in Barry 237). A residual cultural element is usually at some distance from the effective dominant culture, but it is some part of it which is embedded in cultural system. The concept of emergent for Raymond Williams means "the creation of new meaning and values, new cultural practices and new relationships within the dominant structure" (qtd. in Newton 135). It is important to distinguish between those emergent which are elements of new stage of the dominant culture and those which are actually other element or oppositional to dominant system.

Dominant has significant connotation in Cultural Materialism generally and in cultural system specially. Dominant in Williams's terminology is very near to the meaning of Hegemony in Antonio Gramsci's ideology. Hegemony refers to the domination of one people or group by another. According to Gramsci dominant class in the society "makes compromises, provides moral and intellectual leadership and creates institution and social relations in order to establish a basis for the consent of all classes and sections of society" (qtd. in Lodge 301).

Raymond Williams as the founder of Cultural Materialism also insists that politics for its part is always cultural. The history of the Left and the labor movement is the history of attempts to develop an alternative culture a long, complex and contradictory process. 


\section{Review of Literature}

In New Historicism and Cultural Materialism (1998), John Brannigan explains the development of new historicism and cultural materialism and demonstrates both their uses and weaknesses as critical practices. Exemplary readings of Conrad's Heart of Darkness, Gilman's The Yellow Wallpaper, the poetry of Alfred Lord Tennyson and Yeats' Easter 1916 serve to show and criticize the new historicist and cultural materialist interpretative strategies. Brannigan explores the potential future of the theories and the debates surrounding their controversial position in literary studies.

In Cultural Anthropology (1982), Marvin Harris continues to focus on the book's two major objectives. First, this book presents a holistic view of socio-cultural systems, and secondly, the book provides a unified theoretical framework for explaining these systems. It also remains faithful to the belief that anthropologists must routinely deal with facts and theories that are crucial to informed decisions regarding issues of enduring relevance. The cultural approach used throughout furnishes a framework for explaining how the parts of socio-cultural systems are interrelated and how they change over time. The book also continues in its effort to identify the many causal strands that help explain the process of socio-cultural change. It tries to make sense of the many seemingly irrational or arbitrary customs and institutions in small, technologically simple societies as well as complex nations. For anyone interested in the study of culture.

In "Reconceptualizing materialism as identity goal pursuits: Functions, processes, and consequences" (2012), L. J. Shruma et la. propose an expanded conceptualization of materialismthat grounds materialismin research on theself. The article stresses the functions ofmaterialistic goal pursuit, the processes bywhich these functions are developedand implemented, and their potential consequences. This functional perspective views materialisticbehavior as motivated goal pursuit intended to construct and maintain selfidentity, and defines materialismas the extent to which people engage in identity maintenance and construction through symbolic consumption. The article discusses the utility of this conceptualization of materialism in relation to other conceptualizationsand suggests avenues for future research.

In "James Joyce Dubliners: how religion influencesConscience" (2016), MehrdadNazarieh argues that James Joyce's Dubliner is a vividcollection that depicts conflicts that exist between the modern era and the early times of the 20th century interms of beliefs and cultural practices. Joyce advances the significance of Dubliners by providing readers with insights into the current transformed world. According to Joyce, the current era is the type that compels people to know more about the world they live in and fully understand the potential that it possesses. The writer uses life in Dublin to forward his goal by indirectly criticizing its beliefs and exposing certain failures in their fundamental beliefs hence implying that not all beliefs are good. Beliefs can change one's life either to the negative or to the positive depending on the circumstances. In the story of Dubliner, Joyce depicts Dublin to be a city where religious oppression is at optimum and intolerable to the citizens.

\section{Research Method}


The present study is a qualitative research based on theory which is carried out on James Joyce's major short story The sisters, and it will determine concept of religion paralysis within cultural materialist theory. Following cultural path, Williams asserts that the space for alternatives is never entirely blocked: "no mode of production and therefore no dominant social order and therefore no dominant culture never in reality includes or exhausts all human practice, human energy and human intention" (qtd. in Wilson 171). There is always space for opposition, for thinking and action directed towards the elaboration of another social order. In Cultural Materialistic viewpoint the dominant order is not unavoidable real world. In confrontation of the dominant order, according to Williams, we face "a set of identifiable processes of real politic and force majeure, of nameable agencies of power and capital, distraction and disinformation" (qtd. in Lodge 164). The main task of Cultural Materialists is to establish the lines of development for an alternative as Williams stresses:

It is only in a shared belief and insistence that there are practical alternatives that the balance of forces and chances begins to alter. Once the inevitabilities are challenged, we begin gathering our resources for a journey of hope. If there are no easy answers there are still available and discoverable hard answers, and it is these that we can learn to make and share. (qtd. in Wilson

175)

Jonathan Dollimore and Alan Sinfield, the great practitioners of Cultural Materialism, assert that the principle of reliable criticism in political agenda:

Cultural Materialism does not, like much established literary criticism, attempt to mystify its perspective as the natural, obvious or right interpretation of an allegedly given textual fact. On the contrary, it registers its commitment to the transformation of a social order which exploits people on grounds of race, gender and class. (qtd. in Brannigan 98)

Cultural Materialism in achieving its political goals adopts two methods. In some cases it begins to interpret literary texts from the standpoint of oppositional or dissident subculture. In other cases it takes the form of an examination of the material incidents in which conservative ideologies function. Thus, the first way relates to the dissident viewpoint, and the second method is from conservative outlook.

Dissidence in Cultural Materialistic ideology is a very crucial term. Its literal meaning is "the resistance against the dominant order without prejudging an outcome" (Pigspy 151), but according to Sinfield dissidence operates necessarily with reference to the dominant structures: "It has to invoke those structures to oppose them; it means that any position supposes its intrinsic op-position" (Barry 195).

The important point in understanding the meaning of dissidence is that it is not thoroughly opposed to power, and it is not also an antithesis which tries to reverse the values and strategies of power. It is instead very close to the structures of power and indeed is produced by the internal contradictions of these structures. Of course, it implies a deviation from the rules of the dominant culture, but it may be that dissidence achieves no reaction from power.

Recent British Cultural Materialist theory claims reading dissidence in literary texts. Brannigan brings under the question the claim of those critics in investigation of the essence of the dissidence:

It is the idea of conflict and contradiction in Cultural Materialist reading that prepares the ground for incorporation of the dissident within the body 
of the dominant. The power of the dominant culture can only be seen in its containment of the threat of dissidence. In Cultural Materialism dissidence is a phenomenon occurring at specific junctures of the history of a text, which is then subsumed, hence the necessity of Cultural Materialist revitalizations of the dissident perspective. (179)

Concisely the manifestation of Cultural Materialism is "the formation of critical practice in articulating dissident perspectives on contemporary cultural politics" (Higgins 300). Such idea sometimes gives its practitioners a sense of political and social mission.

Cultural Materialism seeks the way in which subversion, dissidence, resistance and all forms of political oppositions could be represented. In this way most of the time it scrutinizes the theatre as "a prime location for the performance of the interaction between the States power and other groups of cultural system" (Wilson and Dutton 12). As we see the first practical attempts of Cultural Materialistic criticism refers to the analysis of the Renaissance Drama.

Abrams argues that Cultural Materialism wants to transfer to the center of cultural study the Marginal or excluded literary works and artistic productions of women, the working class, non-white groups and Third -World culture. Its critics lead their interpretations and their discussion "toward the explicit political end of reforming the existing power-relations which, they consider, are dominated by a privileged gender, race, class or ethnic group" (Glossary of literary terms 254).

By Cultural Materialistic reading of Dubliners (1914), the stories were written when Irish nationalism was at its peak, and a search for a national identity and purpose was raging; at a crossroads of history and culture, Ireland was jolted by various converging ideas and influences. They center on Joyce's idea of an epiphany: a moment where a character experiences a life-changing self-understanding or illumination. Many of the characters in Dubliners later appear in minor roles in Joyce's novel Ulysses. The initial stories in the collection are narrated by child protagonists, and as the stories continue, they deal with the lives and concerns of progressively older people. This is in line with Joyce's tripartite division of the collection into childhood, adolescence and maturity. Dubliners (1914) is certainly important in that he talks within it about his life and his entourage (ibid). It takes a form of naturalistic depiction of Irish middle class in life and around Dublin in the early 20th century. About Dubliners Attridge states that:

The stories are interested in issues of identity and the self, but they are equally involved with issues of politics and what it feels like to be a part of Ireland as a nation with a particular history and a particular place within the British Empire. (90)

Religion is one of the emerging issues in the modern era and forms the backbone of most literary works. Religion as a theme is seen to influence the operation of those who believe in it. Religion is predominated in Dubliners. It forms the functional framework that predetermines ones actions and behavior. James Joyce's Dubliner is a vivid collection that depicts conflicts that exist between the modern era and the early times of the 20th century in terms of beliefs and cultural practices (Parrinder 27). Joyce advances the significance of Dubliners by providing readers with insights into the current transformed world (29). According to Joyce, the current era is the type that compels people to know more about the world they live in and fully understand the potential that it possesses (Ellmann 127). The writer uses life in Dublin to forward his goal by indirectly criticizing its beliefs and exposing certain failures in their fundamental beliefs hence implying that not all beliefs are good. 
Beliefs can change one's life either to the negative or to the positive depending on the circumstances. In the story of Dubliner, Joyce depicts Dublin to be a city where religious oppression is at optimum and intolerable to the citizens (Foster 36).

\section{Discussion}

\section{Social and Religion Paralysis in The Sisters}

In the story, 'The sisters', Joyce uses Dublin as a country whose citizens have a strong belief in religion that they have become slaves to it (Foster 35). Soon enough, though there is no exact explanation of has clearly happened to the priest and what really causes his mental disintegration, the reader knows about the priest from a second hand source and his sister Eliza tells the aunt ant the unnamed boy that everything goes bad after her brother breaks the chalice. After this incident the priest has become odd ,though the broken chalice contained nothing .Significantly Father Flynn's hold of the chalice symbolizes his insecure grasp on spirituality and his failure as a priest (Taglieri 1996,p. 18) and consequently he cannot offer communion and an empty chalice lies on his breast in death (Beja 1973 ,p. 109 ).

The emptiness of the chalice does not enable the clergyman to fulfill the rituals of the Last Supper. In this essence, the void chalice symbolizes the hollowness of Catholicism as a failed institution. Though Eliza is acquainted with the Catholic rites, she offers her guests the sherry and the crackers which symbolize bread and wine. But the unnamed boy refuses to take some and he symbolically he refuses to be part of the ceremony of communion.

The paralysis is the inability of physical movement, but it is also a spiritual, social, cultural, political, and historical malaise (Bulson 36). It does refer to the inability to function correctly and in Dublin's context, it suggests the Dubliners who are naturally paralyzed and they are living a paralyzed city. In the dead Julia Morkans expresses her indignation about the pope who has decided to turn out the women out of the choirs (123).Such decision is unfair on the behalf of females who have singing voices. In The Sisters the one can see that though Father Flynn is a priest, he fails in his religious duties and he presents the real state of Irish Church. Clearly enough, Father Flynn symbolizes the paralyzed Catholic Church and its drawbacks on the individuals, especially children. Yet the old priest teaches the boy great deal of things. The sickness of the spiritual matters affects the social norms and provides an incurable disease in society. This latter becomes helpless and disorientated from its path.

Religion paralysis which occurs on the first page of "The Sisters" in Dubliners. He argues that:

"There was no hope for him this time: it was the third stroke. Night after night I had passed the house (it was vacation time) and studied the lighted square of window: and night after night I had found it lighted in the same way, faintly and evenly. If he was dead, I thought, I would see the reflection of candles on the darkened blind, for I knew that two candles must be set at the head of a corpse. He had often said to me: I am not long for this world and I had thought his words idle. Now I knew they were true. Every night as I gazed up at the window I said softly to myself the word paralysis. It had always sounded strangely in my ears, like the word gnomon in the Euclid and the word simony in the Catechism. But now it sounded to me like the name of some maleficent and sinful being. It filled me with fear, and yet I longed to be nearer to it and to look upon its deadly work."(Joyce 1)

Situation is like the life of people which there is no change. Immediately after presenting there is no hope come to mind of character. The word dead and last word corpse. 
In order to present inertia which characters are suffering and engaging with it. Joyce uses such word "no hope" repetition even in the language of the story. Repetition is going to multiply the same passivity. First line refers to the past which is another repetition that there is no change in paralysis.

Religion is predominated in this story. It mentioned numerously, father Flynn who was always unhappy and usually looked sad. The answer to his disappointment is recognized to the time when he unintentionally broke his chalice. He felt guilty of himself and he had to go to the church and hide himself in darkness just because he felt he had sinned against God. By breaking the chalice, Father Flynn showed dreadful overlook for the vessel that generally carries the holy wine, the transubstantiated blood of Christ, even though the chalice had contained nothing at the time. It is the first evidence in Dubliners that religion is a dangerous and deceptive force. Not only does the chalice cause the priest's madness, it comes back to taunt his dead body. If we put consideration, we will discover that Father Flynn, the disbelieving priest, comes to terms with his sin of breaking the chalice that he even comes to terms with his discovery of the silence of God. And even the boy, who discovers Flynn's concerned past, will be on the verge of making the same discovery, a certain religious kinship between him and the priest. It is his strong belief in religion that immediately edicts his conscience which then has a direct have an effect on his view in his view of life.

Notwithstanding all this, in the same story, most characters seem to be deeply rooted in religion simply from the way they express themselves. The phrase 'may God have mercy upon him' has been over and over said through a variety of characters when referring to the late father Flynn. They all suppose that each and every word they utter is offensive to God in a way. Narrator in this story appears to be extensively affected through what he hears mainly from his seniors. At some factor in the story, he had a dream that was once a result of overmeditating over positive matters that were instructed to him through Cotter. The narrator seems to be appreciably affected his emotions. This is very obvious when he goes with his aunt to the late father Flynn's home. As they pray over the useless corpse, the narrator appears afflicted and tries to think about that the corpse was once smiling at him. As Mr. Cotter discusses with the narrator's parents, he feedback in a assertion on the narrator's relationship with the priest. He says that it is not good for such a young boy to relate with an aged priest. He knew very nicely that father Flynn was a spiritual stereotype and it would be unfair if such beliefs were inculcated into the innocent mind of the younger boy. The researcher strongly believe that Mr. Cotter had viewed how a lot the narrator's sense of right and wrong had been affected. As the narrator considers over the priest's demise, he finds himself thinking about his own death. It is as if there used to be some inner pressure that used to be governing the narrator's idea because on every occasion he idea of anything, something just got here in and sort of redirected his thinking. He was once always crammed with a feeling of guilt. Having been nearer to anybody whose faith was once deeply rooted in the catholic religion, nothing else should be predicted from the narrator other than the beliefs of the late father Lynn. It is something that the narrator can't keep away from due to the fact it comes automatically. Now that the narrator had been uncovered to sturdy beliefs at a highly soft age, the effect on his mind used to be so good sized that everybody should see it from his behavior. In this story, religion is vividly brought out as a major theme and it seems to have a stronger influence on how the people of Dublin carry out their activities. Generally, the writer wants to show how people are tied up by whatever they believe in and as a result how these beliefs affect their consciousness (Parrinder 21). 
Regarding the debut of Joyce as a young believer could bring a perspective on the effects of Catholicism in his stories that would give the impression of a faithful representation of religion in Ireland. Reading Dubliners, the religious aspects of nearly all the stories, but focuses mainly on "The Sisters", "Eveline" and "Grace". Joyce did leave the Church as a young adult and did not return to it.

James Joyce's dissatisfaction with religion, church and priesthood in his short story The Sisters could be better understood if the relationship between the "nets" of Irish society and his view of artist in A Portrait of the Artist as a Young Man (1916) was properly comprehended (1961: 327). One of the "nets" in the Althusserian sense is religion and the Roman Catholic Church with its traditional, stagnant, restrictive and "paralytic" nature and structure, which obviously inhibits the self or the artist from what Joyce metaphorically calls "flight", a "flight" which would avail an artist of chance or opportunity to be free and creative by going beyond ordinary aspects of life shaped by the "nets" of society (327). He represents his frustration with the Catholic Church and priesthood and then artistically critiques the basis, image and authority of the priesthood through different ways and strategies in the story to flee from the dogmatic nature and restraining climate of the religion, he artistically stresses the view that the Catholic Church and Dublin are imbued with "the special odour of corruption which, I hope, floats over my stories' in, or they are the center of paralysis"(Dubliners, 1966: 122-3).

Indeed, "the special odour of corruption" and "paralytic" nature of the town and religion doesn't inspire freedom physically and mentally in life. Religion as having "the special odour of corruption" as well as being "the center of paralysis "Joyce regards the established religion as an important obstruction, which, he thinks, does not allow the artist to create a space of his own to manoeuvre his artistic vision of "flight", vision and vocation beyond the borders of "nets" of Irish society. Their understanding of Catholicism is purposefully perverted by Joyce to expose the limited knowledge of theology among the faithful. Throughout his reading of Dubliners, Joyce was highly attentive in alternating the accuracy and inaccuracy of his characters' knowledge of their faith, and that this demonstrates Joyce's position that Catholicism in Ireland created docility and compliance in the lower class and lower-middle class. Geert Lernout in his book entitled Help My Unbelief (2010) states:

James Joyce and Religion argues that James Joyce lost his faith in the Roman Catholic Church and its dogma and that the historical conditions of Joyce's loss of his faith provide an inescapable context for reading Joyce's works. Lernout explains the beliefs and practices of the Church of Rome that Joyce encountered from the nineteenth century to the beginning of the twentieth century. By attending to the tradition of freethinking writers of the same period, he demonstrates that Joyce's revolt against Christianity was part of a larger network of anti-religious thinking in literature and philosophy. (Lernout 239)

Basirizadeh in his article mentions that, "In de Beauvoir's view if women really want a status, they should deconstruct the structures of the masculine society and present their own definition of feminity. This definition would be the proof of woman's presence and existence counter-intuitive to masculine canon of knowledge in power"(2).

The sisters is important because it is Joyce's critic on society and religion. This is an example of how one religion is placed as the more superior religion and that is a certain way one should live their life in order to be faithful to their religion. In his first important work, Culture and Society (1958), Williams reviewed the mainly conservative English tradition of 
social thought. Its resonance and appeal depend on how it organized culture, conceived as ideas or ideals of perfection removed from material social life, as a critique of specific largescale changes involving industry, democracy, class and art. In a class divided society, "culture" was opposed to business, urban massification, and possessive individualism. Religion is omni-present in Dubliners, yet the religious people who are supposed to be pious, they instead do awful things and they consequently suffer from their individual choices. The Sisters which are written in italics are the seeds of the paralytic spiritual Dublin of the twentieth century life and the power of these three words has a great spiritual effect on the Dubliners. The very sound of the world. Paralysis casts a morbid fear on the boy as he, every night as I gazed up at the window I said softly to myself the word paralysis. It had always sounded strangely in my ears, like the word gnomon in the Euclid and the word simony in the Catechism (1). Using Joyce's allusion, the Catholic Church is good-for-nothing and Father Flynn represents «the corrupt features of Irish Catholicism, turning spirituality into a burden and torture »(cited in Taglieri 1996, p. 18).In addition to that Paul Dubois believes that the true cause of the increase in mental disease is Roman Catholicism\|(cited in Lowe-Evans 1989,p. 40).

According to almost all feminist scholar's patriarchy refers to rule of the father in a male dominated society as a social and ideological construct which regards men as superior to women. They are of opinion that men's domination over female sexuality is central to women's subordination. In fact, man is the head of the family who controls women's sexuality, labor, production, reproduction and mobility. Moreover, the effect of patriarchy can be traced in politics, public life and economy as well as in all aspects of social, personal, psychological and sexual existence.(Raoufzadeh,60)

This story depicts clearly that the Catholic Church is responsible for a large portion of Irish paralysis. But he also quietly hints at another malefactor England. Raymond Williams believes that in capitalistic system everything is covering by capitalism. We see that religion paralyzed people in stories of Dubliners. Religion has a significant effect on the believers mind and even goes ahead to indicate the kind of life they live.

\section{Conclusion}

In conclusion, this paper intended to analyze concept of religion within Cultural Materialism framework and looked upon their influence and active interaction in building up of society and culture. Moreover, it intended to study how this factor is dominant in shaping the characters ' life and status. In essence, all of these examples serve to convey a sense of dispassion and emptiness. Joyce wanted to make one final attack against the Church that he despised so much during this time of his life. By placing the abovementioned characterizations of the Church within a story so encompassed by emptiness, Joyce's final message to the Church is clear: It is a dead institution, devoid of truth and hypocrisy. Joyce wants it to be known to all people that he believes that there is no truth in the teachings of the Catholic Church, and that it will soon be exposed as a deception. Joyce proclaims in Dubliners anger at a culture he feels is paralyzed by Catholic dogma, British exploitation, its own proponents for self-delusion, alcoholism, and Irish hyperbole and blarney. Joyce introduces complex ideas concerning religion and spirituality, especially regarding his conflict with the Catholic Church. Because of the injustices he saw coming from an institution that claimed to follow God and His teachings, Joyce set out to make these fears known to the rest of mankind. Joyce not only teaches what the Church must do to change, but 
he shows the dangers of what might happen if it fails to do so. He makes it very clear that if it does not change, the Church will collapse. He is obstinate that the Church was an extremely damaged institution, and fell victim multiple times to the lust, anger, hypocrisy, and intolerance that so easily beset the human race.

\section{References}

Abrams, M. H. (1993). A Glossary of Literary Terms. New York: Harcourt Brace Pub.

Barker, Chris. (2004). Cultural Studies: Theory and Practice. London: Sage publication Inc.

Barler, Chris.(2003) Sage Dictionary of Cultural Studies. London: Sage Pub Inc.

Basirizadeh, Fatemeh. (2019). A Comparative Study of the Psychoanalytical Portrayal of the Women Characters by Virginia Woolf and Zoya Pirzad. Britain International of Humanatis and Social Sciences Journal, 1-8.

Bei, Xu. (2008) . On Reproducing Literary Style of Dubliners in Chinese, a Thesis, Shanghai International Studies University.

C. E. Bressler. (2007)Literary Criticism: An Introduction to Theory and Practice. The USA: PearsonPrentice Hall.

Claire, Kilroy. (2010) An Introduction to today's Irish Novelists. Dublin: Ireland Literature Exchange.

Daronkolahee, Esmaeel Najar.(2012) James Joyce's Usage of Diction in Representation of Irish Society in Dubliners: the Analysis of "The Sisters" and "The Dead" in Historical Context, The Journal of International Social Research Volume: 5 Issue: 23, PP. 169174.

Fargnoli, Nicholas A. and Gillespie, Michael P. (2006). Critical Companion to James Joyce: A Literary Reference to His Life andWork, Infobase Publishing, New York .

Freese, Lee and Burke, Peter J. (2009) Persons, Identities, and Social Interaction, Department of Sociology, Washington State University. Advances in Group Processes, Vol.11. Greenwich, Conn.: JAI Press.

Harris, Marvin. (2001) . Cultural Materialism: the Struggle for a Science of Culture, Walnut Creek, California: AltaMira Press. (https://www.google.com/search?q=Harris,+Marvin.+Cultural+Materialism)

Joyce, James. Dubliners: Authoritative Text, Contexts, Criticism. Ed. Margot Norris. New York: W.W. Norton, 2006.

M. J. Smith. (2000) Culture: Reinventing the Social Sciences. Philadelphia: Open University Press.

Raoufzadeh,N. Mohammadhosein,Sh. Zaheri Birgani, Sh. (2019) Analysis of Love, Death, Rebirth and Patriarchy in Two Contemporary Poetess Forough Farrokhzad and Sylvia Plath's Selected Poems. Budapest International Research and Critics Institute-Journal, 56-64.

Prendergast, Christopher. (1995). Cultural Materialism: On Raymond Williams, Volume 9. London, Minneapolis: University of Minnesota Press.

Roughley, Alan (1991.) James Joyce and Critical Theory: An Introduction. Ann Arbor: University of Michigan.

Williams, Trevor L.(2013). Resistance to Paralysis in Dubliners, MFS Modern Fiction Studies Project MUSE. Web. 05 Mar. 